\title{
FOOD WASTE FROM THE VIEW OF CIRCULAR ECONOMY: A SYSTEMATIC REVIEW OF INTERNATIONAL LITERATURE
}

\author{
Omar Ouro Salim \\ Patrícia Guarnieri ${ }^{2}$ \\ Fabrício Leitão ${ }^{3}$
}

\begin{abstract}
The limit of the linear economic model increased the interest in developing a new economic model based on a closed circle. The circular economy (CE) emerges as a model of sustainable, regenerative and restorative development, whose focus is to maintain products, food waste and natural resources at their highest level of usefulness and value over time. This paper aims to discuss the issue of food waste and how to preserve it through CE. The methodological procedure was the Systematic Literature Review (SLR), based on the protocol by Cronin, Ryan \& Coughlan (2008), using the time frame of the last ten years, 2009 to 2019 , considering papers published in international journals. It was clear that there is an accumulation of articles published in European countries, focused on attempts to implement circular models that aim to mitigate food waste, and that the transition to this model is essential due to the depletion of natural resources and negative socio-economic externalities. This work highlights the CE processes and benefits of food waste. In addition, it provides suggestions, management, and policy contributions for future research. The valorization and treatment of food waste could contribute to the mitigation of acute hunger in developing countries and the creation of value in food supply chains (FSC).
\end{abstract}

Keywords: Circular Economy. Food Waste. Food Loss. Systematic Literature Review.

\section{DESPERDÍCIO DE ALIMENTOS SOB A ÓTICA DA ECONOMIA CIRCULAR: UMA REVISÃO SISTEMÁTICA DA LITERATURA INTERNACIONAL}

\section{RESUMO}

O limite do modelo econômico linear aumentou o interesse em desenvolver um novo modelo econômico baseado em um círculo fechado. A economia circular (EC) surge como um modelo de desenvolvimento sustentável, regenerativo e restaurador, cujo foco é manter os produtos, os resíduos alimentares e os recursos naturais em seu mais alto nível de utilidade e valor ao longo do tempo. Este estudo visa discutir a questão dos desperdícios alimentares e como preserválos através da EC. O procedimento metodológico foi a Revisão Sistemática da Literatura (RSL), baseada no protocolo de Cronin, Ryan \& Coughlan (2008), utilizando o cronograma dos últimos dez anos, 2009 a 2019, considerando artigos publicados em revistas internacionais. Ficou claro que há um acúmulo de artigos publicados nos países europeus, focados nas tentativas de implementar modelos circulares que visam mitigar o desperdício alimentar, e que a transição para este modelo é essencial devido ao esgotamento dos recursos naturais e das externalidades socioeconômicas negativas. Este trabalho destaca os processos e benefícios da EC do desperdício de alimentos. Além disso, fornecem sugestões, contribuições gerenciais e políticas para pesquisas futuras. A valorização e o tratamento do desperdício de alimentos poderão contribuir na mitigação da fome aguda nos países em desenvolvimento e na criação de valor nas cadeias de suprimentos alimentares (CSA).

Palavras-chave: Economia Circular. Desperdício Alimentar. Perda Alimentar. Revisão Sistemática da Literatura.

\footnotetext{
${ }^{1}$ Mestre em Gestão Organizacional pela Universidade Federal de Goiás - UFG, Goiás, (Brasil). https://orcid.org/0000-0003-1792-4886 E-mail: ouromar@yahoo.fr

${ }^{2}$ Doutorado em Engenharia de Produção pela Universidade Federal de Pernambuco - UFPE, Pernambuco, (Brasil). Professora adjunta do curso de Administração da Universidade de Brasília - UnB, Brasília. https://orcid.org/0000-00015298-5348 E-mail: patriciaguarnieri@gmail.com

${ }^{3}$ Doutor em Transportes pela Universidade de Brasília - UnB, Brasília, (Brasil). Professor adjunto do departamento de Administração da Universidade de Brasília - UnB. https://orcid.org/0000-0003-4174-544X E-mail: fabriciof@hotmail.com
} 


\section{INTRODUCTION}

The global financial crisis has brought with it a shortage of resources and food, according to Banque Mondiale (2012). For Velenturf \& Jopson (2019), climate change along with food waste problems are due to over-exploitation of natural resources and the growing generation of solid and food waste. For them, political action to return lost natural resources within planetary limits is essential to safeguard human wellbeing, thus achieving a closed-loop system, maintaining the value of raw materials and food waste within a sustainable economy.

According to the Food Security Information Network (FSIN, 2019), more than 113 million people in the world are starving. Food crisis have been recorded mainly in countries such as Yemen, Democratic Republic of Congo, Afghanistan, Ethiopia, Arab Republic, Syria, Sudan, Southern Sudan and Northern Nigeria. These countries represent two-thirds of the total number of people facing food insecurity, totalling approximately 72 million people. Besides, it is perceived that onethird of food destined for human consumption is lost or wasted between the place of production and human consumption (FSIN, 2019).

Therefore, more than 815 million people, or $11 \%$ of the world's population, go hungry (FAO, 2018). In the European Union (EU), some 42.5 million people have not had the means to feed themselves adequately (Statistical office of the European Union-EUROSTAT, 2018).

According to United Nations estimates (2015), the world population could rise to 8.6 billion in 2030 and 9.8 billion in 2050. This forecast of population growth brings with it major challenges. The Food and Agriculture Organization of the United Nations (FAO, 2009) estimates that the world will need 70 per cent more food by 2050, and it is essential to reduce food waste instead of seeking new soils to increase food generation.

While the Ellen MacArthur Foundation (2013) points to alternatives so that potentially wasted food can be reused and transformed into other raw materials through the circular economy business models (CEBM).

As it is a sensitive issue throughout the food chain, several studies have focused on reducing food waste. For example, Creus (2018) worked on the quantification of food waste in Brazilian restaurants. Santos et al. (2019) analyzed engagement strategies to deal with food waste in hospital settings. Santos et al. (2020), discussed the different legislations in force and which are ready to be implemented in Brazil as part of the prevention and reduction of food waste. Matzembacher et al. (2021) analyzed the roles adopted by several stakeholders engaged in a voluntary initiative to reduce food loss and waste in Brazil. For this purpose, the authors conducted direct observations and interviewed 54 food sector stakeholders. They found that their actions and activities vary depending on their positioning at the institutional or value chain level.

In international research, Nurhusna Najwa (2018) examined the valuation of food waste in Malaysia. Liu et al. (2020) studied the characterization of environmental impacts of packaging waste generated by urban food delivery services in China.

Dhir et al. (2020) analyzed the impacts of food waste on hotel services. Other studies have explored a range of related topics, including bottlenecks where food is wasted (Zanini, 2013), sustainable organic waste management and recovery ( $\mathrm{Ng}$ et al., 2019), and waste management in the horticultural sector (McCarthy et al., 2019).

Teigiserova et al. (2019) highlighted, however, transparent valorization of surplus, waste, and food losses in the circular economy. Dora et al. (2021) conducted a systematic literature review over the last 20 years (1998 to 2018) on food waste in the supply chain in developed and less developed countries.

Mourad (2016) wrote an article about recycling, recovery, and prevention of food waste and solutions for the sustainability of food systems in the United States and France. Annosi et al. (2021) explored a study focusing on digitalization within food supply chains to prevent food waste. 
Kulikovskaja \& Aschemann-Witzel (2017) identified different retail initiatives to prevent food waste in Denmark. Dora (2019), studied the collaboration of food supply systematic literature reviews the international publications that relate food losses and waste to solutions based on the circular economy (CE) concept.

Vieira et al. (2021) stated that Covid-19 pandemics has increased the urgency to fight against food waste, especially regarding the redistribution practices aimed at vulnerable people affected. In this context, efforts have been made by the public, private and third sectors to face the food insecurity affecting Brazil after the consequences of the pandemic. Santos and Martins (2021) carried out a systematic literature review on systems of performance measurement of food waste and identified the current state of experimental research about it, the main challenges and trends to implement these systems and evidence that it can be strongly benefited by smart technologies and assets from industry 4.0 .

Deliberador et al. (2021) investigated the food waste in a cafeteria of a Brazilian university. The authors used Spearman's correlation to identify the correlation between food waste and consumers' perception of the reasons behind the generation of waste. As a result of the study, the authors proposed interventions aimed at reducing food waste in university cafeterias.

Several sustainable food chain policies have been developed in the regulations and strategies of developed countries, combining economic, social, environmental, and health development. However, they have not yet been achieved as food insecurity problems persist (Sehnem et al., 2020).

Thus, the objective of this study was to investigate the state of the art of publications related to food waste in the context of the CE, using the Systematic Literature Review (SLR) technique following the Cronin et al. (2008) protocol.

Nonetheless, this paper brings as a contribution the contextualization of the international state of the art of published articles on the efficient reuse of food waste and its transformation into other raw materials with benefits in a closed cycle. The present paper is structured as follows: Part 1 presents the contextualization of the theme, researched problem and objective. Part 2 points out the review of the literature on $\mathrm{CE}$, focusing on food waste. Part 3 lists the materials and research techniques used and details the stages of the systematic literature review. Part 4 presents the results of the research, and part 5 refers to the final considerations.

\section{THEORETICAL BACKGROUND}

\subsection{Food waste}

According to the Food \& Agriculture Organization (FAO), food waste refers to the "disposal or alternative use of food that is safe and nutritious for human consumption" (FAO, 2018). Östergren et al. (2014) define food waste as "any food, and inedible parts of food, removed from the food supply chain (FSC) to be recovered or discarded".

Food waste consists of materials intended for human consumption that are subsequently discarded, lost, degraded, or contaminated. The problem of food waste is on the rise, involving all sectors of waste management, from collection to disposal. Identifying sustainable solutions extends to all contributors in the food supply chains, agricultural and industrial sectors, as well as retailers and final consumers (Girotto et al., 2015). Parfitt et al. (2010) defined food waste as food loss that occurs at the retail and consumer stages, and its generation is related to the behaviour of retailers and consumers.

Definitions of food waste are not universally accepted, which makes it difficult to study and quantify food waste. Different categorizations are generated based on the materials included, the means of production, and management approaches. Various terms have been used interchangeably, such as food loss, food waste, biological waste, and kitchen waste. In addition, often, the same 
terms are used but with different meanings. This is exacerbated when reports are translated (Thyberg \& Tonjes, 2016).

However, the definitions have become more nuanced so that the causes and motivations of the actors involved in food waste are the factors that differentiate food waste from food losses. In general, food waste occurs due to some mismanagement in the food supply chain or the conscious decision to discard edible items. Food waste is seen as avoidable food loss. In light of the ambiguity between food loss and food waste, the terms food loss and food waste have been used by management entities. From a mass quantitative perspective, food loss and food waste are equivalent to food loss since food waste is a subset of loss. Nevertheless, food waste directs the emphasis to the differential processes and conditions that cause avoidable versus non-avoidable food waste. This becomes problematic, however, when discussing the treatment of food that is wasted or discarded because it is inedible. Therefore, the existing literature discusses food loss and food waste collectively due to the impossibility of even conceptually separating them after disposal (Kibler et al., 2018).

After all, food waste is a substantial contributor to environmental change and represents a threat to global sustainability. It is responsible for food waste and surplus food (Ravandi \& Javanovic, 2019).

\subsection{The causes of food waste}

The causes of food waste in low-income countries are mainly related to financial, managerial and technical limitations on harvesting, storage facilities, refrigeration in poor weather conditions, infrastructure, packaging and marketing systems, while in the middle/high-income countries, they are principally related to consumer behaviour, as well as lack of coordination between different supply chain actors. Food is wasted due to quality standards, rejections of food items that are not aesthetically perfect. At the consumer level, excessive purchases and expiration dates cause large amounts of waste, in combination with the careless attitude of consumers (Gustavsson et al., 2011).

According to Aschemann-Witzel et al. (2016), food marketing and retailing contribute to food waste through decisions on date labelling, packaging sizes, design elements and pricing strategies that encourage overbuying, as well as communication that changes consumer priorities.

The increasing amount of food waste is a direct consequence of excessive production, mismanagement and human behaviour. For example, in the United Kingdom, the lack of robust consumer data limits the ability to understand and deal with food waste and the adoption of longterm sustainable prevention strategies (Facchini et al., 2018).

As highlighted by several authors, the generation of food waste at the household level is a highly complex and multifaceted issue, motivated by a variety of reasons and types of behaviour. Families generally have ambivalent attitudes towards waste prevention and face conflicts between good intentions to reduce food waste and personal preferences regarding food safety, taste and freshness. Studies on food waste reveal that people over 65 tend to spend less, and families with children tend to waste more food. In addition, overprovision, systematic storage, misinformation about the expiration date of food, and date labels, as well as a dislike of food waste are, among other important reasons for the disposal of superfluous food (Schanes et al., 2018).

The main causes of food waste come from expired foods, food leftovers, misuse of food, lack of awareness, mixing on labels, inappropriate storage conditions; while food losses come from lack of fertilization of plantations, imprecise application of agrochemicals, incorrect post-harvest handling, adverse weather conditions, lack of technology, improper transportation and logistics, and inoperative packaging in food maintenance (Moraes et al., 2020).

The next section will present the importance of the role of the $\mathrm{CE}$ as an effective way to transform disposable food waste into a new, sustainable product that can be consumed by the increasingly active population, preserving the future generation from possible food crises. 


\subsection{Circular economy}

As presented by the Ellen MacArthur Foundation (EMF), the CE has its origins in the literature of economics (Boulding, 1966; Pearce \& Turner, 1990), industrial ecology (Frosch \& Gallopoulos, 1989; Lifset \& Boons, 2012) and corporate sustainability (Lovins et al., 1999; Benyus 2002; McDonough \& Braungart, 2002; Stahel, 2016; Guide \& Van Wassenhove, 2009; Pauli, 2010), whose concepts have begun to impact the business and industrial communities.

One of the purposes of the $\mathrm{CE}$ is the relentless pursuit of waste elimination. In this sense, the idea is to maintain the value of products and materials for a long time, aiming at minimizing resources and extending the useful life of products (EMF, 2012).

The $\mathrm{CE}$ is a systemic approach to economic development designed to benefit business, society and the environment in contrast to the linear model characterized by "produce-consumeeliminate". It is regenerative by design and aims to gradually decouple growth from the consumption of finite resources (EMF, 2012).

Korhonen et al. (2018) state that the CE is designed from production and consumption systems that maximize the service produced from the linear flow of nature and energy, using cyclic material flows, renewable energy sources and cascading type energy flows. There is not a consolidation of the concept of the circular economy, according to the same authors, and theoretical background should evolve in the field. The successful CE can solve the problems of food waste in all dimensions (social, economic and environmental) of the food chain (Barret, 2017), considering that this model plans the reduction of the resources at the beginning of the value chain and some strategies to mitigate the waste at the end of the cycle.

The CE refers to the restoration and change in the way of thinking of the industrial economy by intention and design. In this sense, the products are designed to favour disposal, disassembly, conversion or recycling. It is the reuse of recovered materials, of products at the end of life, to the detriment of the extraction of natural resources, which represents the basis of economic growth (EMF, 2013). In the food chain, it is applicable mainly in the biological cycles defined by EMF (2013), considering that the food waste can be valuable to new industrial processes and products.

The CE goes against the Linear Economy (LE), as it is a short-term concept that meets less of the future needs of humanity (Murray et al., 2015). Since the industrial revolution, the Western world has based its economy on a linear model (Le Moigne, 2014). The linear concept has the idea of extracting resources from the environment, transforming these resources through industrial processes, distributing them to consumers and thus, discarding them in landfills. The circular concept goes against this idea extending the cycle and reusing the waste in a new process, at the same time that reduces the use of resources, energy and water from the design (Guarnieri et al., 2020).

Globalization has contributed to the LE being the most used mode of operation by food chain actors. This concept is based on extracting, manufacturing, consuming and disposing of, in which natural resources are extracted and used to produce products that will be consumed by final consumers, from which waste will result (Le Moigne, 2014).

Already in the 20th century, Karl Marx warned of the impossibility of success of the linear model, in which nutrients are extracted from the soil in the form of food without ever returning to nature (Barret, 2017).

Figure 1 shows the contrast between the two approaches, focusing on CE rather than LE and their benefits to humanity. 
Figure 1. Main action keys for the transition in a circular economy.

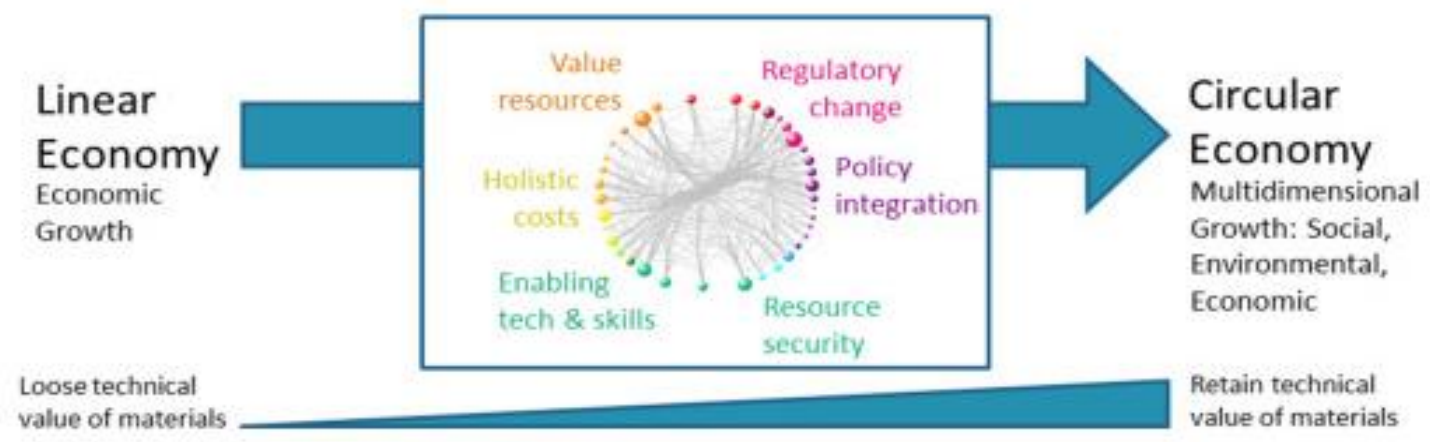

Source: Velenturf \& Jopson (2019).

The CE is an approach that needs to move beyond the LE model, which depends on large amounts of natural resources and is increasingly inadequate to social, economic and environmental realities (EMF, 2015).

The $\mathrm{CE}$ is an approach currently promoted and encouraged in both public and private initiatives in several countries, such as China, Japan, the United Kingdom, France, Canada, Netherlands, Sweden and Finland (Korhonen et al., 2018). The EU has estimated that the transition to a $\mathrm{CE}$ can create annual economic gains for the European manufacturing sector, and the global economy would benefit from a $\$ 1,000$ billion annual gain (COM, 2015; CIRAIG, 2015).

China has adopted a law for the CE since 2008 (CIRAIG, 2015), and is suggested as an approach aligned with economic and sustainable development (EMF et al., 2015; EMF, 2013; CIRAIG, 2015; COM, 2015; COM, 2014), however, there are still several barriers to the implementation of the CE (Korhonen et al., 2018).

Figure 2 presents, in a systemic manner, the main concepts and strategies that have been adopted by the CE, as defined by EMF (2015). 
Figure 2. Circular economy systemic diagram.

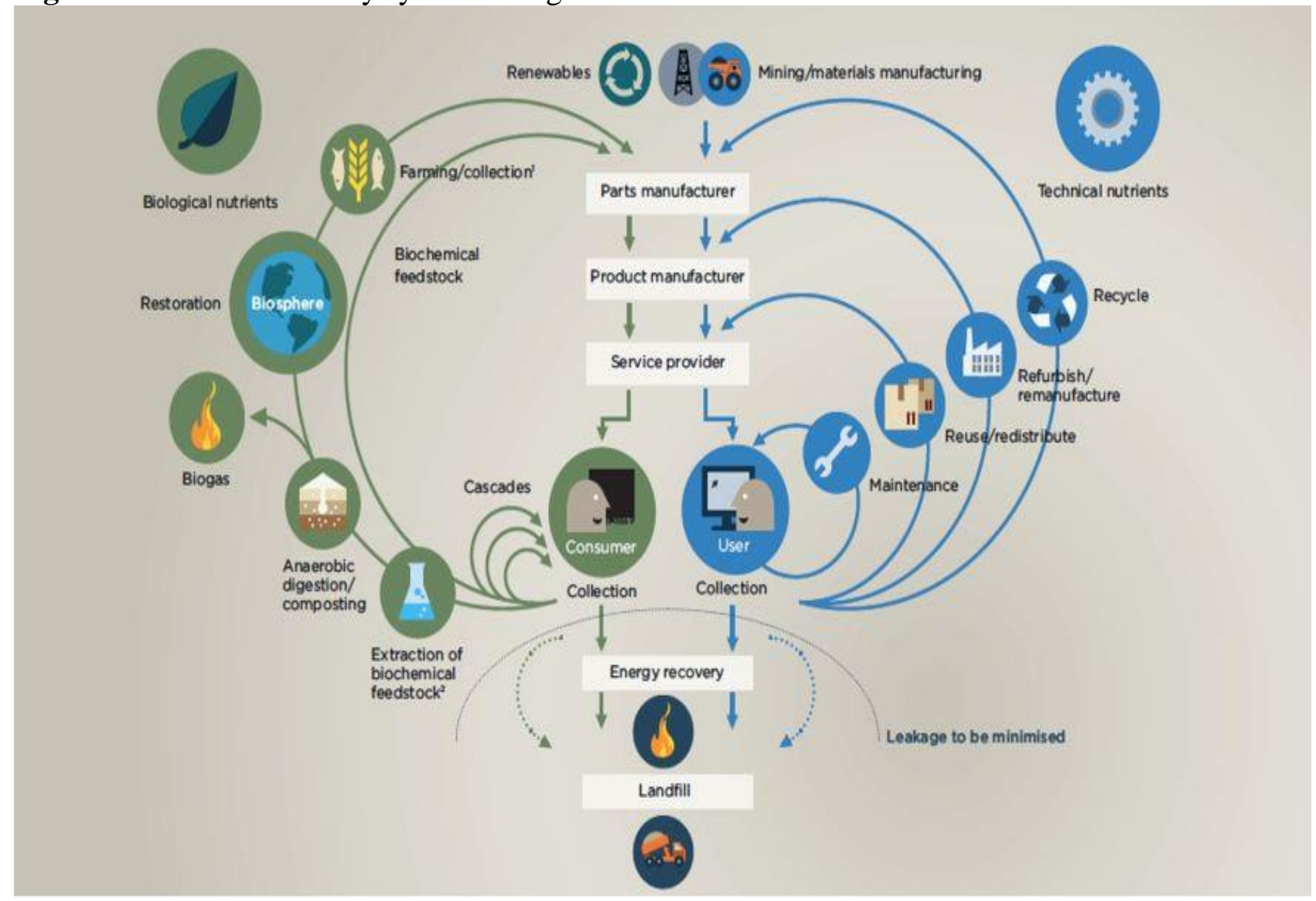

Source: EMF (2015).

CE proposes growth through the reduction, extraction, transformation and reuse of waste, carried out in closed cycles, a global production system, acting in each stage of the productive sector to minimize the extraction of natural resources and reduce food waste. It involves all stakeholders in the production chain, from production to waste management, while ensuring economic growth with the reduction of food waste (Barret, 2017).

Nevertheless, in Brazil, there is no national strategy to implement a circular model. However, there are some policies, programs, and plans that, in a certain way, seek sustainable development through circular practices and work with related topics. In this sense, the PNRS was established, which was the first public policy to be adopted in waste management, discussing several management tools used in circular economies. The PNRS aims to face the problems related to the inadequate management of solid waste. In this framework, topics such as CE have become a focus of discussion (Confederação Nacional da Indústria, 2019).

Through the CE, the inclusion of short food supply circuits may allow the reduction of intermediaries, leading to a reduction in the route and transport costs, reducing the use of nonrenewable resources, such as oil, besides allowing better traceability of products and, thus, a better judgement on the agricultural techniques used for food production (Gallaud et al., 2016).

\subsection{Prevention of food waste through circular economy business models}

The management of food waste in the context of the CE can be observed in several aspects according to the recovery and valorization models. In this logic, measures for the treatment, measurement and control of food waste generated are indispensable. Likewise, food waste should be valued, aiming at social, economic and environmental results. In addition, through the 
composting model, compounds can be used to enrich soils affected by environmental degradation and thus contribute to the development of agriculture by generating healthy food for the population (Unger \& Razza, 2018).

Borrello et al. (2017) point out that, through the regenerative system of the CE, the expired food products returned to retail can enter the production process of new products of animal origin.

However, the CE seeks to implement material regeneration practices. To this end, it has introduced the concept of the cascade. Cascade usually occurs through networks of factories in which organic products, instead of being deposited in landfills, are used as inputs for new products. In this way, food waste becomes a substrate to supply the integrated treatment plants that ensure various foods from biomass under the context of biorefineries (Clark et al., 2012).

In this perspective of valorization, food waste can be used as food for animals, vegetables, fish and humans, as well as for the production of fertilizers. The study by Cheng et al. (2015) points to the valorization of food waste collected in hotels and restaurants for animal consumption.

Furthermore, Martins et al. (2016), in their studies, evaluate the possibility of reusing vegetable waste as raw material in animal feed industries. In their studies, it was found that plant by-products are nutritionally and sanitary appropriate for animal consumption.

However, Tampio et al. (2015) mention in their studies that food waste plays a role as fertilizer in agriculture. Thus, through its models, the CE transforms food waste into raw materials to reduce environmental impacts and generate new economic opportunities (Borrello et al., 2017).

Nevertheless, the CE covers all activities aimed at the reduction, reuse and recycling of materials throughout the agrifood supply chain (Murray et al., 2015). It emphasizes the minimization of food waste, turning it into a new resource that can be used as a new product. It also offers several economic opportunities in the recovery of food waste (Mohan et al., 2016).

Some countries, such as Brazil have inter-sectoral strategies aiming the reduction of food losses and waste, Matzembacher et al. (2021) identified the main stakeholders involved: Federal government (through all Ministries participation), food banks, food start-ups addressing food waste issues, international organizations/agencies, the media, multi-stakeholder networks, nongovernmental organizations, processing industries, public companies, retailers, social movements, and universities/researchers.

In the following session will be presented the problem of the study and the protocol of systematic literature review.

\section{METHOD}

\subsection{Research characterization}

This study is classified as descriptive and qualitative research. Qualitative descriptive studies are indicated to gather information whose phenomenon is still little understood (Kim et al., 2017).

The technical procedure used was the literature review. It should be noted that there are basically two types of literature review: traditional or narrative literature review and systematic literature reviews. The SLR uses a more rigorous and defined approach to review the literature in a specific area; therefore, it provides the critical analysis of articles from the study area in question (Cronin et al., 2008).

The content analysis technique of Bardin (1977) was used to analyze and interpret the articles found since they can be adjusted to check common themes according to the inquiry of key elements in each study, transforming these individual findings into new interpretations (Polit \& Beck, 2006).

The preparation of an article selection script is essential to demonstrate the gap in the scope of research, as well as to assist the production of this study. For this purpose, the Cronin et al., (2008) protocol was used, a methodological procedure composed of five steps, presented in Table 1. 
Table 1. Steps of the Cronin, Ryan and Coughlan Protocol (2008).

\begin{tabular}{|c|c|}
\hline Steps & Characteristics \\
\hline $\begin{array}{l}\text { Definition of the search } \\
\text { question }\end{array}$ & $\begin{array}{l}\text { What are the main characteristics of the international literature on food waste reduction } \\
\text { within the CE? }\end{array}$ \\
\hline $\begin{array}{l}\text { Definition of the set of } \\
\text { inclusion and exclusion } \\
\text { criteria }\end{array}$ & $\begin{array}{l}\text { The criteria cover the selected scientific basis, publication period, article types, keywords, } \\
\text { and Boolean operators. Due to the fact that the theme concerning the CE is } \\
\text { multidisciplinary, and that it can be found in journals of several areas, it was defined that } \\
\text { the research would occur in the scientific bases Scopus, Web of Science and Taylor \& } \\
\text { Francis in which they are multidisciplinary and include articles from journals with a high } \\
\text { impact factor and from all areas. The publication period was then established, which } \\
\text { covers articles published from } 2009 \text { to } 2019 \text {. As for keywords, the words in English were } \\
\text { defined: Circular Economy AND Food Waste. }\end{array}$ \\
\hline $\begin{array}{l}\text { Literature selection and } \\
\text { access }\end{array}$ & $\begin{array}{l}\text { Regarding the types of articles, it was defined that only complete articles published in } \\
\text { journals would be covered, which excluded articles published in conference proceedings, } \\
\text { dissertations, theses, patents, books and book chapters' errata, among others. As far as the } \\
\text { Boolean operators used are concerned, only the AND was chosen, excluding the NOT and } \\
\text { OR operators. For the first selection, the articles should deal with the recovery and } \\
\text { valorization of food waste according to the reading of the title and abstract. A total of } 90 \\
\text { articles were identified in the period from } 2009 \text { to } 2019 \text {, of which, after reading the } \\
\text { abstracts, } 79 \text { articles were excluded because they did not properly address the topic of } \\
\text { Food Waste in the context of the CE. }\end{array}$ \\
\hline $\begin{array}{l}\text { Quality assessment of } \\
\text { the literature included } \\
\text { in the review }\end{array}$ & $\begin{array}{l}\text { Of the } 90 \text { articles, only } 11 \text { were found to fit the research theme, and there was a repetition } \\
\text { of } 27 \text { articles in the three ( } 3 \text { ) chosen bases and the other } 52 \text { were eliminated for distancing } \\
\text { themselves from the theme related to food waste in the context of the CE. The remaining } \\
11 \text { articles were filed and compiled, highlighting the aspects related to the research } \\
\text { question previously defined in step 1, involving: authors, publication period, sub-problem } \\
\text { related to food waste in the context of the CE. }\end{array}$ \\
\hline $\begin{array}{l}\text { Analysis, synthesis and } \\
\text { dissemination of results }\end{array}$ & $\begin{array}{l}\text { This stage covered the analysis of each article, necessary for the analysis and } \\
\text { interpretation of published work. Thus, tables, charts and figures with the main criteria } \\
\text { used and their authors were prepared. The eleven (11) papers were rigorously analyzed. }\end{array}$ \\
\hline
\end{tabular}

Source: Authors.

Figure 3 summarizes the process of search and filtering that was conducted in February 2020. Firstly, a total of 90 documents were identified. Secondly, after eliminating duplicate articles (present in more than one of the three chosen bases), the researchers read the titles, abstracts and keywords of the papers, and thus, the articles (27) that did not adhere to the scope of the research were excluded. Then, 11 articles adhered to the proposal. It should be noted that in this last filter were excluded papers that did not deal with the concept of CE or that were not applied to the area of food waste. 
Figure 3. Steps of the research process.

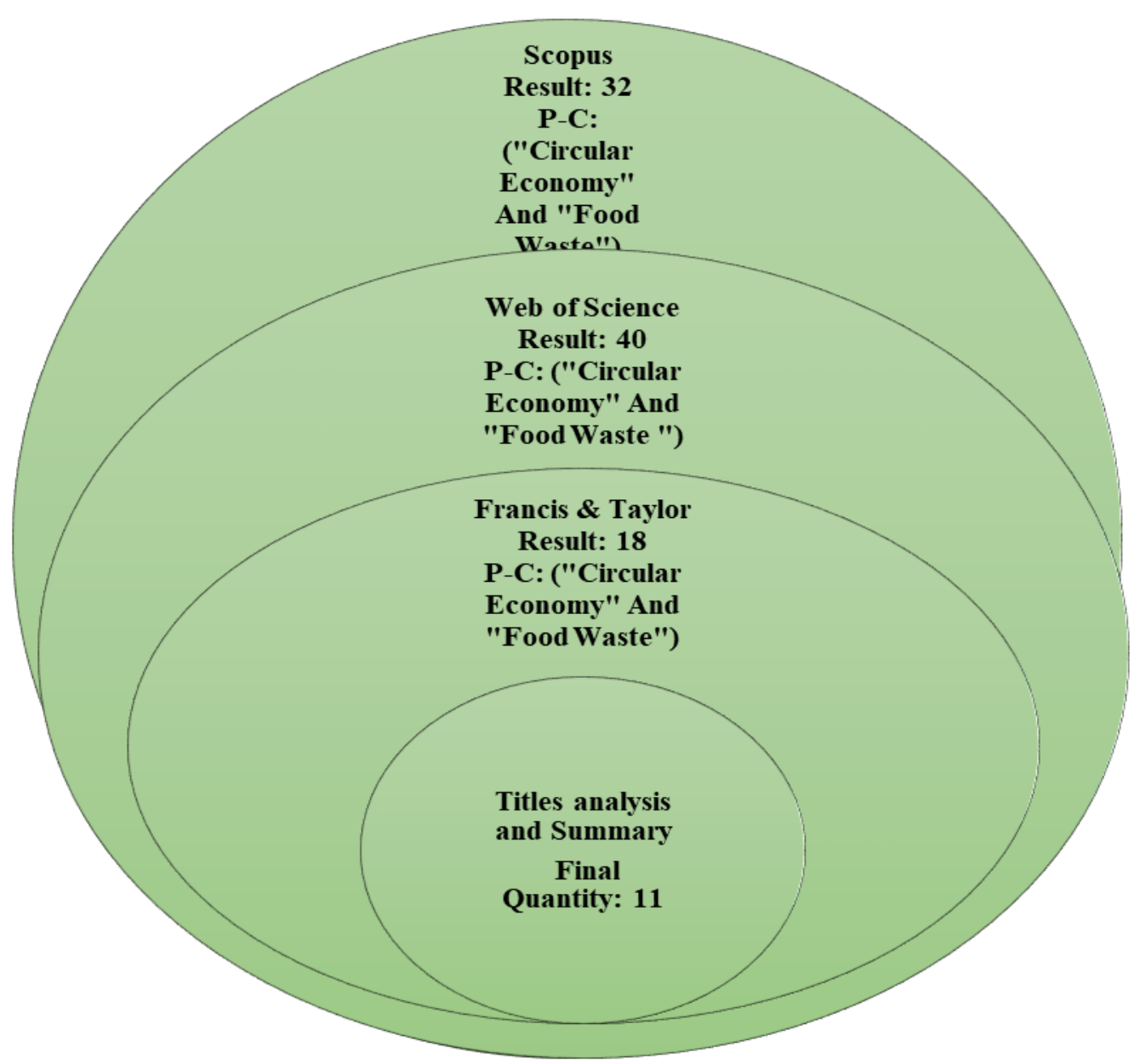

Source: Authors.

Considering all the searches made in international journals, only 11 papers had adherence to the scope of the research. Therefore, the full papers were read to extract as much information as possible, and their results will be presented in the next section, using the support of content analysis, as proposed by Bardin (1977).

According to Bardin (1977), there are three (3) categories of analysis which are I) preanalysis, ii) document exploration and, iii) processing of results, inference, and interpretation. Subsequently, the results can be categorized, which, according to the author, is an operation of classification, differentiation, and grouping of essential elements in the content of the articles.

The categorization was carried out a priori and allowed the analysis and reading of the content of the selected documents. The categories defined in this analysis were related to the categorization of the articles analyzed: i) International literature on food waste in the context of the circular economy; ii) Gaps and research agenda; iii) Policy and managerial implications.

\section{RESULTS AND DISCUSSIONS}

In the 11 articles, analyzed 43 different authors were identified, with an average of approximately four (4) authors per article.

Most studies took the quantitative approach (55\%), followed by the qualitative approach (36\%). In addition, (9\%) they are mixed and combined both approaches and are classified as descriptive. 
Regarding methods, procedures and techniques used in the papers, the percentage of articles that used the respective options of each methodological category were illustrated. It was observed that the majority are of a theoretical-empirical nature (55\%), with six (6) articles focused on observation, description, analysis and exploration of theories through which the authors seek to find a sustainable solution to the problems of food waste. None of which were found in the theoreticalmodel studies $(0 \%)$ and on the theoretical review side $(18 \%)$ of the papers, and the interview appears as the data collection instrument $(27 \%)$.

\subsection{International literature on food waste in the context of the circular economy}

The selected papers show that the international literature is restricted and scarce in relation to the theme of food waste within the $\mathrm{CE}$, and after the searches, only eleven articles were identified in three international databases. Figure 4 exemplifies their evolution, with a comparison of the papers found in the literature review of this study, and below are the papers mentioned in the SLR.

Figure 4. Publication per Year.

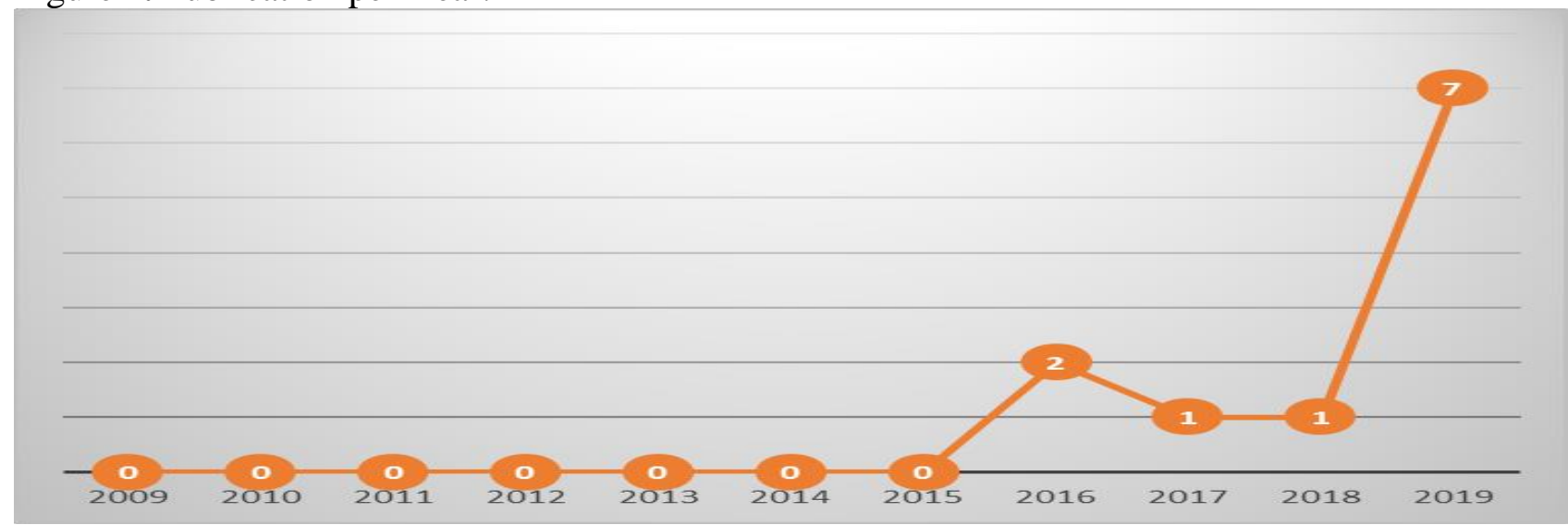

Source: Authors.

It can be seen that in Figure 4, from the year 2016 on, researchers are beginning to take more interest in the topic related to food waste in the context of the CE. To highlight the need for research on the subject, data from FAO (2018) show that by 2050, the world will have 2.3 billion people to feed. To meet the food demands of the future generation, it is necessary to increase the production capacity by about $70 \%$, which attracts the attention of researchers, particularly in the search for new production models to mitigate the increase in food waste through the $\mathrm{CE}$, which aims to produce zero waste (Roos, 2014).

Of these works, the publication period is concentrated between 2018 and 2019 for the works identified in the SLR, and all deal with food waste in the European and Canadian context with various recovery solutions within the CE. This highlights the topicality of the subject and shows a particularity in the valorization of food waste as raw materials.

For Paralinska \& Pagare (2018), the topic of food waste has still been little discussed in academia. For the authors, one of the main research problems being formulated concerns the measurement of the amount of food lost and wasted in the current world. The Scopus database includes 1256 articles on "food waste, food wastage and food losses" in the title or keywords (in social sciences and economics). This emphasizes the need to investigate more about the theme, due to the low number of publications, given the importance of the theme (Paralinska \& Pagare, 2018).

To support the statement, Figure 4 shows that in the years 2009 to 2015, no publication was found regarding food waste through the different models of the CE. This shows the research gap.

However, financing circular models are not without its challenges due to the different forms of investments, such as use performance contracts (ING, 2015). Roos (2014) highlights the financial 
problems encountered in effectively implementing circular models. For the author, collective financial participation is an emerging approach that can be adapted to the growth of the circular business, as foreseen in the principles of the CE.

To assist in the transition to a circular model, the design of the CE should move towards an open innovation platform (Rauch et al., 2016). However, this raises questions about the robustness and quality of the product, its integrity and intellectual property implications (Srai et al., 2016).

Besides that, various EU instruments have an effect on the behaviour of different actors in the food chain, which can result in an increase or decrease in the amount of wasted food. The EU has the potential to influence food waste through the different funds at its disposal and the different arrangements linked to the functioning of the actors in the food supply chain. It can also influence the reduction of food waste through the different policies defined by the European Commission as the Common Agricultural Policy, the Common Fisheries Policy, the Food Safety Policy and the Waste Policy (European Court of Auditors, 2016).

Moving on to discuss the types of research raised in SLR, Sörme et al. (2019) are concerned about problems of considerable food waste dumped in landfills. For them, recycling is the best way to achieve the transition to the $\mathrm{CE}$ in order to achieve the sustainable development goals set by the European Union (EU). Within the framework of this study, the performance of households in relation to different coloured bags was tested.

Later, Corrado \& Sala (2018) pointed out in their studies that environmental pollution, resource depletion, food waste represent a considerable inefficiency for the global food system. In his paper, a review of existing studies on the generation of food waste on a European scale was carried out. In this sense, ten studies were selected among relevant scientific articles and grey literature with quantification methodologies. The elements discussed by the authors were the waste streams captured by estimates, the distinction between edible and inedible food waste along the food chain, reported units of measurement, general inefficiencies of the food system and data uncertainty.

Sörme et al. (2019) suggest that decision-maker should clearly define their policy objectives (prevention, recovery, waste management, food safety) to optimize the efficiency and effectiveness of quantitative food waste data collection. Paralinska \& Pagare (2018) support the same thinking by highlighting the idea of collaboration among supply chain actors to build an accounting framework to quantify food waste generated.

Van Bemmel \& Parizeau highlight that food waste has several economic and environmental repercussions, and there is growing political attention to it in Canada. The authors investigate the material characteristics of wasted food and its management in the city of Guelph, Ontario. In this regard, 33 semi-structured interviews were conducted with actors in the local food value chain, including farmers/producers, distributors, retailers, food service providers. The study shows that food is not wasted simply by throwing food away, so it sometimes happens because the food has a certain type of aesthetic defect or because the food is visibly spoiled.

Pérez-Camacho et al. (2018) discussed the assessment of environmental impacts of the life cycle of substitution of food waste in raw materials through anaerobic digestion (AD). According to Pérez-Camacho et al. (2018), food waste represents an essential element in the countries' economies. In this context, the prevention and reuse of food waste remain one of the main objectives of the United Nations 2030 agenda that stipulates the fight against food waste in the world. The techniques of reconverting food waste into raw materials in developed countries should reach developing countries where food insecurity problems and landfills are greatest (Kinobe et al., 2015).

Besides, it can be seen that the recovery or processing of food waste goes through chemistry. In this context, it can be deduced that chemistry represents an important factor in the recovery or transformation of waste and in the transition to a CE. From this point of view, Ferreira et al. (2017) declare that chemistry represents a facilitating element to drive the CE with lower operational and raw material production costs. 
However, DeLorenzo et al. (2019) show in their work the project carried out by the Ontario government to eradicate food waste problems. In this project, the government instigated a restructuring of waste management legislation. It stipulates that Ontario move towards waste management on CE model, with emphasis on extended producer and importer responsibility.

With that same sustainable development feature, Secondi et al. (2019) are concerned about the increase in food waste in the European Union. In this perspective, they launch an appeal for a more sustainable transition to the CE. In this context, the study focused on the supply chain of tomato sauce with a triple objective. First, the food waste generated along the tomato sauce supply chain from cultivation to retail was quantified; second, the related causes were examined; and third, the extent to which food waste can be reused according to the CE approach was assessed.

By adopting the Food Waste and Loss Accountancy and Reporting Standard (FLW Standard), which provides requirements and guidance for quantifying and reporting food weights, the analyses focused on the production of tomato sauce in Italy. It was revealed that this supply chain could be considered a true example of the CE, where almost nothing is lost as more than $85 \%$ of total food waste was valued in alternative sectors or activities such as animal consumption, renewable energy production and donations to charities.

Later, Mihai \& Grozavu (2019) draw our attention to the increase in food waste in rural areas. For them, improving the efficiency of collection, better law enforcement and the vigilance of environmental authorities, along with educational and environmental awareness, are necessary steps to combat them. In this sense, they suggest for some rural families the implementation of conventional composting methods and special platforms for organic waste storage through regional systems and waste management in order to add value to food waste.

However, the study developed by Erceg \& Margeta (2019) points out that there are several methods of food waste management. For them, there are two specific methods that should be considered, along with their positive and negative impacts when doing this type of study in a small space such as the Vis Island. These two specific methods are the discharge of food waste into the sewer system and the transport of food waste to treatment facilities.

Castrica et al. (2018) highlighted that food waste and by-products represent phytochemical sources such as phenols and antioxidant compounds that can be used as functional ingredients in animal consumption. This study contributes to the current knowledge on the functional role of food waste and agrifood by-products. The results indicate that agrifood waste and by-products represent a source of phenols and antioxidant molecules.

In general, the reuse of agrifood waste and by-products as functional ingredients in animal nutrition is crucial, not only because it reduces disposal costs and the amount of food waste but also because of the promising potential of functional ingredients for animal feeding (Rebucci et al., 2019). In this study, one can see the importance of the role of chemistry in the transformation of food waste into other forms of raw material.

Regarding the increase in food waste, Jurgilevich et al. (2016) applied the concept of CE in a food supply chain through a social-technical system towards sustainability. The study contributes to the understanding of changes in food consumption patterns. For the authors, consumers play an important role in the transition to $\mathrm{CE}$ through more sustainable choices. For them, the pace of the transition is influenced by actors in the food supply chain through the reduction and reuse of surplus food.

However, Laso et al. (2016) pointed out that large amounts of food waste generated can benefit the economy of any country by closing the product life cycle. In this paper, the recovery of food waste was measured using the Life Cycle Assessment (LCA) tool. For the authors, food waste (fish thorns and fish meat waste) can be recovered by producing fishmeal and oil or biogas through $\mathrm{AD}$. In addition, the valorization of food waste by means of $\mathrm{AD}$ has an environmentally better profile than incineration and landfill. For the authors, innovation in packaging and new forms of technologies to come will play a key role in preventing food waste. 
According to Table 2 below, it is perceived that most papers addressed the recovery of food waste from the angle of theoretical modelling; the recovery of food waste was discussed from the perspective of chemistry using chemical catalysts and, lastly, the recovery of food waste using methods of classification, recycling and sorting as anaerobic digestion, which is more used in developed countries and which proves to be effective than other methods such as pyrolysis, composting, incineration, Promethee and quantification methods.

Quantification has been shown to be a major factor in counting and accounting for food waste. The issue of industrial symbiosis was also raised at work, as the authors suggest that through a digital platform, companies and industries, households and supermarkets could exchange unusable food waste or surplus, which could help the economy of countries and reduce food waste.

In addition, the authors have noted issues of awareness of the actors of the agro-food chain to food waste. Hence, it is necessary to awaken awareness through strict environmental laws. Moreover, the papers do not propose a single model of circular economy to be followed by families, supermarkets, companies, academics and industries to contain food waste issues. Therefore, it can be seen that each article provides similar and sometimes different solutions, as shown in Table 2 .

Table 2. Similitude and difference between the authors' works.

\begin{tabular}{|c|c|c|}
\hline Author / Year & Research Focus & Main Results \\
\hline $\begin{array}{l}\text { Corrado \& Sala (2018); Van } \\
\text { Bemmel \& Parizeau (2019); } \\
\text { DeLorenzo et al. (2019); Sörme } \\
\text { et al. (2019); Secondi et al. } \\
\text { (2019); Mihai \& Grozavu } \\
\text { (2019). }\end{array}$ & $\begin{array}{l}\text { Knowledge and awareness of } \\
\text { food waste }\end{array}$ & $\begin{array}{l}\text {-Collaboration of the actors; } \\
\text {-Social and environmental responsibility; } \\
\text {-Environmental regulations and legislation. } \\
\text {-Reducing environmental impacts. }\end{array}$ \\
\hline $\begin{array}{l}\text { Pérez-Camacho et al. (2018), } \\
\text { Erceg \& Margeta (2019); } \\
\text { Jurgilevich et al. (2016); Laso et } \\
\text { al. (2016). }\end{array}$ & Use of circular models & $\begin{array}{l}\text {-These papers addressed the recovery of food } \\
\text { waste from the angle of theoretical modelling as } \\
\text { Life Cycle Assessment (LCA), composting, } \\
\text { Anaerobic Digestion (AD), biorefining, } \\
\text { quantification, promethee, industrial symbiosis, } \\
\text { recycling and sorting. }\end{array}$ \\
\hline Castrica et al. (2019) & Chemical benefits & $\begin{array}{l}\text {-The recovery of food waste from the } \\
\text { perspective of chemistry using chemical } \\
\text { catalysts. }\end{array}$ \\
\hline
\end{tabular}

Source: Authors.

In the context of this study, it is observed that, although the CE proposes several solutions for the prevention, reduction and valorization of food waste, there are still research gaps in the agrifood supply chains. However, the scope of the studies is different. The main concerns of the authors were the prevention and reduction of food waste using the principles of circular economy through regenerative and restorative systems and the creation of values for society.

\subsection{Gaps and research agenda}

Based on the analysis of the papers, we identified that most studies focused on developed countries. In addition, no study on food waste were identified within the CE in African countries that are the most vulnerable country, considering the context of food insecurity (FAO, 2018). In addition, it is noted that most researchers are more concerned with the rapid resolution of food waste issues in developed countries than in developing countries that suffer more from food waste at the beginning of production (processing, distribution and consumption) (Gustavsson et al., 2011), mainly considering some bottlenecks in the logistics infrastructure.

Li et al. (2016) point out that most developing countries still do not fully implement the recycling of food waste and the circular economy discussions are still in the state of infancy, as stated by Guarnieri et al. (2020). As a result, most food waste is mixed with solid waste and then 
landfilled, a low parcel of this food waste is composted to produce natural fertilizer or used to feed animals. In addition, environmental legislation remains inapplicable, and most aid for recycling activities and projects comes from international organizations while developing countries set a low budget for segregating waste treatment activities and facilities. As a result, problems of inadequate management of food waste in developing countries arise from incompatible administrative measures and precarious budget allocations for improving recycling activities. Most developing countries still do not have restrictive legislation or national plans to reduce food waste; when they have, it is more related to the donation of food waste (Li et al., 2016).

Matzembacher et al. (2021) pointed out that the institutional environment in emerging countries, such as political instability, logistical bottlenecks, deficient distribution infrastructure, asymmetrical power and cultural particularities, must be considered when solutions are proposed to solve food waste and losses problems.

Moreover, food waste is linked to the growth of the middle classes in emerging countries. Few studies so far have investigated household food waste in emerging countries (AschemannWitzel et al., 2019). The same has been observed throughout the systematic literature review of the international papers, as we have encountered few articles that talk about food waste in developing countries.

Scholars point to the need to use quantification techniques to reduce food waste in agrifood supply chains, particularly in milk value chains (Wesana et al., 2019).

There is a lack of studies that take a systematic approach to account for food waste by providing disaggregated values by stage of the food supply chain and by food groups. Such an approach could support policymakers in prioritizing food waste reduction interventions (Caldeira et al., 2019).

There is a shortage of understanding about the most effective food waste prevention measures to be implemented. The food waste puzzle can be considered in several respects, depending on the position of stakeholders in the chain. In this sense, several measures can be implemented to mitigate food waste in the chains, such as diet valuation, consumer awareness, and a set of redistribution measures (Diaz-Ruiz et al., 2019).

Despite their generally negative attitude towards food waste, consumers often follow goals that may inhibit their intention to reduce food waste (Barone et al., 2019).

CE practices in European companies, although gradual, face certain common barriers such as administrative processes, regulations and lack of human resources to start their operations, while companies that have not implemented CE measures consider the financing, investment and costbenefit barriers the most significant (Garcés-Ayerbe et al., 2019).

In this context, it is essential to implement a strict environmental law to require the collection and prevention of food waste in retailers, restaurants, homes, among others, through a digital platform as suggested by professionals. The government should also encourage the donation of surplus food to charities and vulnerable populations. In addition, the government should encourage the purchase of products based on recycling by the target public, thus lowering the tax rates of recycled products.

The lack of robust consumer data in developed and developing countries limits the ability to understand and deal with food waste and to adopt effective long-term sustainable prevention strategies (Facchini et al., 2018).

Nowadays, with the development of technologies and intelligent assets from the 4.0 industry, such as the Internet of Things (IoT), Blockchain, Big Data, the monitoring and tracking of food remains easier and more reliable for an effective control for the prevention of food waste at different stages of the production chain. However, in the case of this study, the concern related to the use of the above-mentioned technologies was not discussed, as they are still in an embryonic stage in the productive food chain. Therefore, for future research, we suggest the use of the Internet of Things (IoT), Blockchain, Big Data as methods of recovery, treatment and valorization of food waste (Dora et al., 2021; Jabbour et al., 2020). 
The circular economy refers to a development model in which the waste of one company becomes the raw material of another. The use of technology should aim to improve not only business processes but also their sustainability. For this reason, Industry 4.0 and the circular economy are candidates to be the two sides of the same coin (Garcia-Muiña et al., 2019). However, it is essential to pay attention to the quality of food waste generated because some biological contamination can cause poisoning, so quality and food safety standards must be followed in the food industry, when waste from other processes are considered as raw material.

It can be seen that there is still a long way to go in the context of reducing food waste due to the constant production of large agrifood industries and the marketing effects that often encourage the consumption of new products on the market. On the other hand, the planet's natural resources are rapidly diminishing, and food insecurity is increasing, particularly in developing countries (Diaz, 2017).

Industries and companies have, in part, an important role to play in the fight against food waste because throughout the agrifood supply chain, there are opportunities for waste reduction, reuse and recycling (KPMG, 2020).

Scholars play an active role in achieving relevant results in the conceptualization of the CE in the food sectors in relation to the reduction of food waste. In addition, decision-makers should focus their efforts on implementing the most desirable and shortest loop retention techniques, such as remanufacturing, reconditioning and reuse (Reike et al., 2018).

Researchers should think about doing a field survey integrating all supply chain actors through interviews, workshops, surveys, focus group and case studies, ethnographic and phenomenological, in order to better understand the main causes of food waste in the value and production chains and solve them instead of focusing only on positivist models, as observed in SLR.

The actors involved in the agrifood supply chains need to make clear the categories of the different organic waste recovered to decide the most appropriate way to deal with them. Once this distinction is made, it is essential to seek the best possible destination for the latter (Teigiserova et al., 2019).

It is important to highlight that, although the circular economy models are applied to food waste, the latter is therefore not a one-size-fits-all solution. In this context, scholars could explore other very specific and more appropriate sustainable models or indicators that could support the circular models to be in the prevention, reduction and valorization of food waste (Esposito et al., 2020).

\subsection{Policy and managerial implications}

$\mathrm{CE}$ approaches have received increasing attention from governments, scientists, political and business actors in recent years, as they respond to economic, social and environmental needs. The concept of $\mathrm{CE}$ arises with different approaches and priorities in different developed countries (Rouquet \& Nicklaus, 2014).

The first strategic foundations of CE were initially designed to focus on waste management but gradually evolved to include more systemic approaches, largely driven by the Ellen MacArthur Foundation. In this sense, the CE principles were extended to 6Rs (Reuse, Recycle, Redesign, Remanufacture, Reduce, Recover) (Liu et al., 2018).

For example, CE law in Germany aims to reduce the use of natural resources through waste disposal, focusing on closed-loop recycling. In 2000, Japan launched the "Sound Material Cycle Society" to engage in solid waste management. However, two European countries most considered efficient in terms of waste recycling are Germany and the Netherlands. Germany was one of the first countries to adopt a law based on the CE principles updated in 2012. The Netherlands has also integrated this closed-loop waste approach by creating a National Management Plan from 2009 to 2021, with a focus on moving towards a material chain policy. CE, in its broadest sense, is a model 
of economic growth that involves ecological poles and economic opportunities. Regardless of countries, it relies on a scarcity of resources to develop new technologies and products that are more resource-efficient and with less environmental impact (Rouquet \& Nicklaus, 2014; Ghisellini et al., 2016; Mourad, 2016; Korhonen et al., 2018).

Changing our food system is one of the most important things in tackling climate change, creating healthy cities, and rebuilding biodiversity, as the linear system has fueled urbanization, economic development and supported a growing population fast. However, it came at a huge cost to society and the environment. Policymakers and practitioners in countries can seize the opportunity to change the global food system through three approaches: first, supplying food grown regeneratively; secondly, designing and marketing healthy food products; third getting the most out of food (EMF, 2021).

Regarding enabling a CE to fight food waste, there are several international policies independently of each country. For example, China advocates using strict management policies to involve local authorities and businesses in the circular turn. Japan uses a combination of four modes of environmental management policies to promote the development of $\mathrm{CE}$ in companies. In Germany, different government agencies work in collaboration with private entities, and the Netherlands has chosen to use the "Cradle to Cradle" approach in its economic, social and environmental development policy and in promoting a policy of industrial symbiosis (Rouquet \& Nicklaus, 2014).

For example, in Brazil, there are some laws on the donation of food by retail food establishments to needy people or charities, which can help in reducing food insecurity in Brazil (Brazil, 2020). In addition, there are numerous Non-Governmental Organizations that recover and sell imperfect food from retailers to the population at cheap prices (Creus, 2018).

Organic waste is the most recurrent in developing countries (Kinobe et al., 2015). There is not yet a national food waste prevention and reduction directive to be adopted by the various actors in the food chain in developing countries (Dora et al., 2021). In addition, Teigiserova et al. (2019) pointed out that there is not yet a clear and universal definition of food waste, which makes it difficult to characterize and adequately treat it in rich and developing countries. In this context, it is necessary to implement policies focused on the prevention of food waste to control the current problems of food insecurity in both developed and developing countries. Also, the management and recovery of food waste can represent opportunities to reduce poverty and unemployment in our society, particularly in Brazil.

\section{CONCLUSIONS}

Considering the importance and necessity of the discussion of the food waste topic in the context of the $\mathrm{CE}$, issues related to economic, social and environmental dimensions should be incorporated. More research is still needed to investigate the relationship between $\mathrm{CE}$ and food waste, which were the focus of this paper, as well as their influences on the performance of new innovative sustainable development models for the prevention, reduction and valorization of food waste in developed and developing countries.

Food waste represents an alarming situation that needs to be solved. In fact is a danger for our planetary system accompanied by food insecurity pointed out by international institutions, scholars and professionals.

From this perspective, the CE model appears as a solution to eradicate food waste problems, transforming the latter into raw materials through a closed and regenerative cycle. The circular model is composed of various waste recovery models such as composting, logistic reverse, anaerobic digestion, incineration, pyrolysis, biorefining, quantification and industrial symbiosis. Although these methods require more financial investment, it is worthwhile implementing them in each country to reduce the harmful effects of food waste on the environment. However, researchers 
report throughout this study that anaerobic digestion is the most efficient and effective method from an environmental point of view.

On the other hand, the importance of chemistry in the processing of food waste into raw materials is highlighted. In this sense, it is necessary an environmental education in the academic environment as high school, higher education where students have already had contact with chemistry. Besides, the government needs to implement in schools and colleges a specific education in favour of the $\mathrm{CE}$ and its benefits in the valorization of food waste in a country's economy.

The relevance of the number of publications in recent years $(2016,2017,2018$ and 2019) is noticeable but still concentrated in developed countries. Nevertheless, cities and regions could reduce the waste burden if they encouraged circular thinking as a way to distribute unsold food. Therefore, some researchers point out that public policy in European countries follows technological development and not circular thinking.

Additionally, researchers point out that financial incentives for sending surplus food into anaerobic digestion facilities can help in the current strengthening of circular thinking that serves in the regeneration of food waste.

Therefore, preserving food self-sufficiency considering social, economic and environmental issues will always be a challenge for our generation. The search for solutions to the problem of food waste is part of the path to a successful and sustainable transition to circularity even if there are still a number of barriers and restrictions that must be overcome.

As a result, there is still a lack of public policies capable of dealing with and efficiently combating the problems of food waste that are increasing in developed and developing countries, as pointed out by some researchers in the field and international institutions.

CE needs to be developed by supply chain actors in compliance with the rules and their principles. To promote the CE concept, governments must adopt different modes of environmental management policies, such as coercion, collaboration, regulatory framework, volunteerism.

The limitations of this work refer mainly to the choices made regarding the chosen search protocol, the applied filters, the time cut and the selected scientific bases. Besides, the work did not exhaust national and international literature (journals, bases, event proceedings, theses, dissertations, books).

In addition to the research agendas already suggested, future studies may choose other bases and protocols to compare results. It is believed that the $\mathrm{CE}$ deserves to gain the robustness necessary to continue growing, not only in academia but also in public and private organizations.

Finally, this study contributed to a theoretical overview of the evolution of international publications on food waste, pointing out different methods used by researchers and different circular models proposed in developed countries with their social, economic and environmental benefits for the academic community and society in general.

\section{REFERENCES}

Aschemann-Witzel, J., de Hooge, I., \& Normann, A. (2016). Consumer-related food waste: Role of food marketing and retailers and potential for action. Journal of International Food \& Agribusiness Marketing, 28(3), 271-285.

Aschemann-Witzel, J., Giménez, A., \& Ares, G. (2019). Household food waste in an emerging country and the reasons why: Consumer's own accounts and how it differs for target groups. Resources, Conservation and Recycling, 145, 332-338.

Banque Mondiale (2012). Selon la Banque Mondiale, la pauvreté extrême recule, mais certains facteurs de vulnérabilité persistent. Communiqué de Presse. (Accessed on 13 March 2018).

Bardin, L. (1977). Tradução de Luis Antero Neto e Augusto Pinheiro. Análise de conteúdo. 
Barone, A. M., Grappi, S., \& Romani, S. (2019). "The road to food waste is paved with good intentions": When consumers' goals inhibit the minimization of household food waste. Resources, Conservation and Recycling, 149, 97-105.

Barret, A. (2017). Les apports de l'économie circulaire dans la consommation de produits alimentaires en vrac. Mémoire publié, Toulouse, France.

Benyus, J. (2002). Mother Nature's School of Design. Choices for Sustainable Living, 8, 34p.

Borrello, M., Caracciolo, F., Lombardi, A., Pascucci, S., \& Cembalo, L. (2017). Consumers' perspective on circular economy strategy for reducing food waste. Sustainability, 9(1), 141.

Boulding, K.E., (1966). The economics of the coming spaceship earth. In: Jarrett, H. (Ed.), Environmental Quality Issues in a Growing Economy. Johns Hopkins University Press, Baltimore, MD.

Caldeira, C., De Laurentiis, V., Corrado, S., van Holsteijn, F., \& Sala, S. (2019). Quantification of food waste per product group along the food supply chain in the European Union: a mass flow analysis. Resources, Conservation and Recycling, 149, 479-488.

Castrica, M., Rebucci, R., Giromini, C., Tretola, M., Cattaneo, D., \& Baldi, A. (2019). Total phenolic content and antioxidant capacity of agrifood waste and by-products. Italian Journal of Animal Science, 18(1), 336-341.

Cheng, Z., Mo, W. Y., Man, Y. B., Lam, C. L., Choi, W. M., Nie, X. P., ... \& Wong, M. H. (2015). Environmental mercury concentrations in cultured low-trophic-level fish using food waste-based diets. Environmental Science and Pollution Research, 22(1), 495-507.

CIRAIG (International Reference Centre for the Life Cycle of Products Processes and Services), 2015. Circular Economy: A Critical Literature Review of Concepts. Canada, Montreal.

Clark, J. H., Luque, R., \& Matharu, A. S. (2012). Green chemistry, biofuels, and biorefinery. Annual review of chemical and biomolecular engineering, 3, 183-207.

COM (European Commission), (2014). Towards a Circular Economy: A Zero Waste. Programme for Europe, Brussels. Belgium.

COM (European Commission), (2015). Closing the Loop. An EU Action Plan for the Circular Economy, Brussels. Belgium.

Confederação Nacional da Indústria. Economia circular oportunidades e desafios para a indústria brasileira. (2019). https://www.portaldaindustria.com.br/publicacoes/2018/4/economia-circularoportunidades-e-desafios-para-industria-brasileira/. (Accessed on 24 february 2020).

Corrado, S., \& Sala, S. (2018). Food waste accounting along global and European food supply chains: State of the art and outlook. Waste management, 79, 120-131.

Creus, C. A. (2018). Prevenção do desperdício alimentar sob a avaliação de ciclo de vida: ferramenta e aplicação em casos práticos. Tese de doutorado. http://www.producao.ufrj.br/index.php/en/theses-anddissertations/doutorado/2018/678--600/file. (Accessed on 24 february 2020).

Cronin, P., Ryan, F., \& Coughlan, M. (2008). Undertaking a literature review: a step-by-step approach. British journal of nursing, 17(1), 38-43.

Deliberador, L. R., Batalha, M. O., Chung, M., \& César, A. D. S. (2021). Food waste: Evidence from a university dining hall in Brazil. Revista de Administração de Empresas, 61. 
DeLorenzo, A., Parizeau, K. and von Massow, M. (2019), "Regulating Ontario's circular economy through food waste legislation", Society and Business Review, Vol. 14 No. 2, pp. 200-216. https://doi.org/10.1108/SBR-12-2017-0115.

Dhir, A., Talwar, S., Kaur, P., \& Malibari, A. (2020). Food waste in hospitality and food services: A systematic literature review and framework development approach. Journal of Cleaner Production, 270, 122861.

Diaz L. F. Waste management in developing countries and the circular economy. Waste Management \& Research. 2017;35(1):1-2. doi:10.1177/0734242X16681406.

Diaz-Ruiz, R., Costa-Font, M., López-i-Gelats, F., \& Gil, J. M. (2019). Food waste prevention along the food supply chain: A multi-actor approach to identify effective solutions. Resources, Conservation and Recycling, 149, 249-260.

Dora, M. (2019). "Collaboration in a circular economy: learning from the farmers to reduce food waste", Journal of Enterprise Information Management, Vol. 33 No. 4, pp. 769-789.

Dora, M., Biswas, S., Choudhary, S., Nayak, R., \& Irani, Z. (2021). A system-wide interdisciplinary conceptual framework for food loss and waste mitigation strategies in the supply chain. Industrial Marketing Management, 93, 492-508. https://doi.org/10.1016/j.indmarman.2020.10.013.

ECA European Court of Auditors. (2016). Fighting food waste: an opportunity for the EU to improve resource efficiency in the food supply chain. https://www.eca.europa.eu/Lists/ECADocuments/SR16_34/SR_FOOD_WASTE_EN.pdf $>$. Accessed 11 March 2020.

Erceg, O., \& Margeta, J. (2019). Selection of food waste management option by Promethee method. EGFOS, 10(19), 87-97.

Esposito, B., Sessa, M. R., Sica, D., \& Malandrino, O. (2020). Towards circular economy in the Agrifood sector. A systematic literature review. Sustainability, Vol. 12, No. 18, p. 7401.

Facchini, E., Iacovidou, E., Gronow, J., \& Voulvoulis, N. (2018). Food flows in the United Kingdom: The potential of surplus food redistribution to reduce waste. Journal of the Air \& Waste Management Association, 68(9), 887-899.

FAO. (2009). The state of food insecurity in the world: economic crises - impacts and lessons learned. Rome: FAO. http://www.fao.org/docrep/012/i0876e/i0876e00.htm. (Accessed on 24 September 2019).

FAO. (2018). The State of Food Insecurity in the World. Rome: FAO.

Ferreira, P. G., da Silva, F. C., \& Ferreira, V. F. (2017). A Importância da Química para a Economia Circular. Revista Virtual de Química, 9(1).

Frosch, R. A., \& Gallopoulos, N. E. (1989). Strategies for manufacturing. Scientific American, 261(3), 144153.

FSIN, Food Security Information Network. Global Report on Food Crises. (2019). http://www.fsinplatform.org/sites/default/files/resources/files/GRFC_2019-Full_Report.pdf. (Accessed on 25 february 2020).

Gallaud, D., Laperche, B. (2016). Économie circulaire et développement durable: écologie industrielle et circuits courts. London, UK: ISTE Editions, $149 \mathrm{p}$. 
Garcés-Ayerbe, C., Rivera-Torres, P., Suárez-Perales, I., \& Leyva-de la Hiz, D. I. (2019). Is it possible to change from a linear to a circular economy? An overview of opportunities and barriers for European small and medium-sized enterprise companies. International journal of environmental research and public health, 16(5), 851.

Garcia-Muiña, F. E., González-Sánchez, R., Ferrari, A. M., Volpi, L., Pini, M., Siligardi, C., \& SettembreBlundo, D. (2019). Identifying the equilibrium point between sustainability goals and circular economy practices in an Industry 4.0 manufacturing context using eco-design. Social Sciences, 8(8), 241.

Ghisellini, P., Cialani, C., \& Ulgiati, S. (2016). A review on circular economy: the expected transition to a balanced interplay of environmental and economic systems. Journal of Cleaner production, 114, 11-32.

Girotto, F., Alibardi, L., \& Cossu, R. (2015). Food waste generation and industrial uses: a review. Waste management, 45, 32-41.

Guarnieri, P., Cerqueira-Streit, J. A., \& Batista, L. C. (2020). Reverse logistics and the sectoral agreement of packaging industry in Brazil towards a transition to circular economy. Resources, conservation and recycling, 153, 104541.

Guide Jr, V. D. R., \& Van Wassenhove, L. N. (2009). OR FORUM-The evolution of closed-loop supply chain research. Operations research, 57(1), 10-18.

Gustavsson, A., Svensson, M., Jacobi, F., Allgulander, C., Alonso, J., Beghi, E., \& Gannon, B. (2011). Cost of disorders of the brain in Europe 2010. European Neuropsychopharmacology, 21(10), 718-779.

ING. (2015). Rethinking Finance in a Circular Economy. https://www.ingwb.com/media/1149417/ingrethinking-finance-in-a-circular-economy-may-2015.pdf. (Accessed on september 2016).

Jabbour, C. J. C., Fiorini, P. D. C., Ndubisi, N. O., Queiroz, M. M., \& Piato, É. L. (2020). Digitally-enabled sustainable supply chains in the 21st century: A review and a research agenda. Science of the Total Environment, 725, 138177.

Jurgilevich, A., Birge, T., Kentala-Lehtonen, J., Korhonen-Kurki, K., Pietikäinen, J., Saikku, L., \& Schösler, H. (2016). Transition towards circular economy in the food system. Sustainability, 8(1), 69.

Kibler, K. M., Reinhart, D., Hawkins, C., Motlagh, A. M., \& Wright, J. (2018). Food waste and the foodenergy-water nexus: a review of food waste management alternatives. Waste management, 74, 52-62.

Kim, H., Sefcik, J., Bradway, C. (2017) Characteristics of Qualitative Descriptive Studies: A Systematic Review. Research in Nursing \& Health, 40(1), 23-42.

Kinobe, J. R., Bosona, T., Gebresenbet, G., Niwagaba, C. B., \& Vinnerås, B. (2015). Optimization of waste collection and disposal in Kampala city. Habitat International, 49, 126-137.

Korhonen, J., Honkasalo, A., \& Seppälä, J. (2018). Circular economy: the concept and its limitations. Ecological economics, 143, 37-46.

KPMG. (2020). Fighting Food Waste using the circular economy. https://assets.kpmg/content/dam/kpmg/au/pdf/2019/fighting-food-waste-using-the-circular-economyreport.pdf. (Accessed on 30 November 2020).

Laisney, C., Soyeux, A., \& Redlingshöfer, B. (2013). Les gaspillages et les pertes de la «fourche à la fourchette» Production, distribution, consommation. Document de travail du centre d'études et prospective. Paris, France. 
Laso, J., Margallo, M., Celaya, J., Fullana, P., Bala, A., Gazulla, C., ... \& Aldaco, R. (2016). Waste management under a life cycle approach as a tool for a circular economy in the canned anchovy industry. Waste Management \& Research, 34(8), 724-733.

Le Moigne, R. (2014). L'économie circulaire: comment la mettre en oeuvre dans l'entreprise grâce à la reverse supply chain? Dunod. Paris, France.

Li, Y., Jin, Y., Li, J., Chen, Y., Gong, Y., Li, Y., \& Zhang, J. (2016). Current situation and development of kitchen waste treatment in China. Procedia environmental sciences, 31, 40-49.

Lifset, R., \& Boons, F. (2012). Industrial ecology: Business management in a material world. In The Oxford handbook of business and the natural environment. Edited by P. Bansal e A. Hoffman. London. UK. Oxford University Press. http://dx.doi.org/10.1093/oxfordhb/9780199584451.003.0017.

Lovins, A.B., Lovins, L.H., \& Hawken, P. (1999). A road map for natural capitalism. Harvard business review, 77 (3), 145-58, 211.

Liu, G., Agostinho, F., Duan, H., Song, G., Wang, X., Giannetti, B. F., ... \& Lega, M. (2020). Environmental impacts characterization of packaging waste generated by urban food delivery services. A big-data analysis in Jing-Jin-Ji region (China). Waste Management, 117, 157-169.

Liu, Z., Adams, M., \& Walker, T. R. (2018). Are exports of recyclables from developed to devel-oping countries waste pollution transfer or part of the global circular economy? Resources, Conservation and Recycling, 136, 22-23.

MacArthur, E. (2012) "Towards the circular economy: economic and business rationale for an accelerated transition." Report commissioned by the Ellen MacArthur Foundation, London, UK.

MacArthur, E. (2013). Towards the circular economy. Journal of Industrial Ecology, 2, 23-44.

MacArthur, E. (2015). Rumo à economia circular: O racional de negócio para acelerar a transição. Report commissioned by Ellen MacArthur Foundation. London, UK.

MacArthur, E. (2021). Food and the circular economy. Retrieved from:https://www.ellenmacarthurfoundation.org/explore/food-cities-the-circular-economy (accessed June 2021). (Accessed on 15 september 2021).

Martins, M. L., Rodrigues, S. S., Cunha, L. M., \& Rocha, A. (2016). Strategies to reduce plate waste in primary schools-experimental evaluation. Public health nutrition, 19(8), 1517-1525.

Matzembacher, D. E., Vieira, L. M., \& de Barcellos, M. D. (2021). An analysis of multi-stakeholder initiatives to reduce food loss and waste in an emerging country-Brazil. Industrial Marketing Management, 93, 591-604.

McCarthy, B., Capetanaki, A. B., \& Wang, P. (2019). Circular agri-food approaches: Will consumers buy novel products made from vegetable waste? Rural Society, 28(2), 91-107.

McDonough, W., \& Braungart, M. (2002). Design for the triple top line: new tools for sustainable commerce. Corporate Environmental Strategy, 9(3), 251-258.

Mihai, F. C., \& Grozavu, A. (2019). Role of Waste Collection Efficiency in Providing a Cleaner Rural Environment. Sustainability, 11(23), 6855.

Mohan, S. V., Nikhil, G. N., Chiranjeevi, P., Reddy, C. N., Rohit, M. V., Kumar, A. N., \& Sarkar, O. (2016). Waste biorefinery models towards sustainable circular bioeconomy: critical review and future perspectives. Bioresource technology, 215, 2-12. 
Moraes, C. C., de Oliveira Costa, F. H., Pereira, C. R., da Silva, A. L., \& Delai, I. (2020). Retail food waste: mapping causes and reduction practices. Journal of Cleaner Production, 256, 120124.

Murray, A., Skene, K., \& Haynes, K. (2015). The Circular Economy: An Interdisciplinary Exploration of the Concept and Application in a Global Context. Journal of Business Ethics, 1-12.

Nations, U. (2015). World population prospects: The 2015 revision. United Nations Econ Soc Aff, 33(2),166.

Ng, K. S., Yang, A., \& Yakovleva, N. (2019). Sustainable waste management through synergistic utilization of commercial and domestic organic waste for efficient resource recovery and valorization in the UK. Journal of Cleaner Production, 227, 248-262.

Nurhusna Najwa, H. (2018). Quantifying waste reduction and revenue saved based from converting food waste to liquid compost/Nurhusna Najwa Hussin (Doctoral dissertation, University of Malaya).

Östergren, K., Gustavsson, J., Bos-Brouwers, H., Timmermans, T., Hansen, O. J., Møller, H., et al. (2014). Definitional framework for food waste, full report. FUSIONS project. https://www.eufusions.org/phocadownload/Publications/FUSIONS\%20Definitional\%20Framework\%20for\%20Food\%20 Waste\%202014.pdf. (Accessed on 27 february 2019).

Parfitt, J., Barthel, M., \& Macnaughton, S. (2010). Food waste within food supply chains: quantification and potential for change to 2050. Philosophical transactions of the royal society B: biological sciences, 365(1554), 3065-3081.

Parlinska M., Pagare A. (2018). Food Losses and Food Waste Versus Circular Economy. Problems of World Agriculture, 18(2), 228-237.

Pauli, G. A. (2010). The blue economy: 10 years, 100 innovations, 100 million jobs. Paradigm publications.

Pérez-Camacho, M. N., Curry, R., \& Cromie, T. (2018). Life cycle environmental impacts of substituting food wastes for traditional anaerobic digestion feedstocks. Waste Management, 73, 140-155.

Polit, D. F., \& Beck, C. T. (2006). Essentials of nursing research: Methods, appraisal, and utilization (Vol. 6, No. 8). Edited by Lippincott Williams \& Wilkins. 554p.

Rauch, E., Dallasega, P., \& Matt, D. T. (2016). Sustainable production in emerging markets through Distributed Manufacturing Systems (DMS). Journal of Cleaner Production, 135, 127-138.

Ravandi, B., \& Jovanovic, N. (2019). Impact of plate size on food waste: Agent-based simulation of food consumption. Resources, Conservation and Recycling, 149, 550-565.

Reike, D., Vermeulen, W. J., \& Witjes, S. (2018). The circular economy: new or refurbished as CE 3.0? exploring controversies in the conceptualization of the circular economy through a focus on history and resource value retention options. Resources, Conservation and Recycling, 135, 246-264.

Roos, G. (2014). Business model innovation to create and capture resource value in future circular material chains. Resources, 3(1), 248-274.

Rouquet, R., \& Nicklaus, D. (2014). Études \& documents Comparaison internationale des politiques publiques en matière d'économie circulaire. 57. Retrieved from http://www.developpementdurable.gouv.fr/Comparaison-internationale-des.html. (Accessed on 12 january 2020).

Santos, C, W., Guimarães, C., \& Junior, Á, E. (2019). O engajamento para combate ao desperdício de alimentos nos hospitais como estratégia de responsabilidade social corporativa. Amazônia, Organizações e Sustentabilidade, 8(1). 
Santos, K. L. D., Panizzon, J., Cenci, M. M., Grabowski, G., \& Jahno, V. D. (2020). Perdas e desperdícios de alimentos: reflexões sobre o atual cenário brasileiro. Brazilian Journal of Food Technology, 23.

Santos, P. H. A., \& Martins, R. A. (2021). Food Waste and Performance Measurement Systems: A Systematic Review of the Literature. Revista de Administração de Empresas, 61.

Schanes, K., Dobernig, K., \& Gözet, B. (2018). Food waste matters-A systematic review of household food waste practices and their policy implications. Journal of Cleaner Production, 182, 978-991.

Schweitzer, M. D., Calzadilla, A. S., Salamo, O., Sharifi, A., Kumar, N., Holt, G., ... \& Mirsaeidi, M. (2018). Lung health in era of climate change and dust storms. Environmental research, 163, 36-42.

Secondi, L., Principato, L., Ruini, L., \& Guidi, M. (2019). Reusing food waste in food manufacturing companies: the case of the tomato-sauce supply Chain. Sustainability, 11(7), 2154.

Sehnem, S., Pereira, S. C. F., Godoi, D., Pereira, L. H., \& Junior, S. S. (2020). Food waste management: An analysis from the circular economy perspective. Environmental Quality Management, 31(1), 59-72.

Sörme, L., Voxberg, E., Rosenlund, J., Jensen, S., \& Augustsson, A. (2019). Coloured plastic bags for Kerbside collection of waste from households - to improve waste Recycling. Recycling, 4(2), 20.

Srai, J. S., Harrington, T. S., \& Tiwari, M. K. (2016). Characteristics of redistributed manufacturing systems: a comparative study of emerging industry supply networks. International Journal of Production Research, 54(23), 6936-6955.

Stahel, W. R. (2016). The circular economy. Nature, 531(7595), 435-438.

Tampio, E., Ervasti, S., \& Rintala, J. (2015). Characteristics and agronomic usability of digestates from laboratory digesters treating food waste and autoclaved food waste. Journal of Cleaner Production, 94, 8692.

Teigiserova, D. A., Hamelin, L., \& Thomsen, M. (2019). Review of high-value food waste and food residues biorefineries with focus on unavoidable wastes from processing. Resources, Conservation and Recycling, 149, 413-426.

The statistical office of the European Union (Eurostat), How is the EU progressing towards the circular economy? https://ec.europa.eu/eurostat/documents/2995521/8587408/8-16012018-AP-EN.pdf/aaaaf8f475f4-4879-8fea-6b2c27ffa1a2. (Accessed on 24 February 2020).

Thyberg, K. L., \& Tonjes, D. J. (2016). Drivers of food waste and their implications for sustainable policy development. Resources, Conservation and Recycling, 106, 110-123.

Tian, F. (2018). An information system for food safety monitoring in supply chains based on HACCP, blockchain and internet of things (Doctoral dissertation, WU Vienna University of Economics and Business).

Turner, R. K., \& Pearce, D. W. (1990). The ethical foundations of sustainable economic development. International Institute for Environment and Development Publications Library. London WC1V 7DN, UK.

Unger, N., \& Razza, F. (2018). Food waste management (sector) in a circular economy. In Designing Sustainable Technologies, Products and Policies (pp. 127-132). Springer, Cham.

Van Bemmel, A., \& Parizeau, K. (2019). Is it food or is it waste? The materiality and relational agency of food waste across the value chain. Journal of Cultural Economy, 1-14.

Velenturf, A. P., \& Jopson, J. S. (2019). Making the business case for resource recovery. Science of the total environment, 648, 1031-1041. 
Vieira, L. M., Barcellos, M. D. D., Araujo, G. P. D., Eriksson, M., Dora, M., \& Matzembacher, D. E. (2021). Desperdício de alimentos: desafios e oportunidades em operações sustentáveis. Revista de Administração de Empresas, 61.

Wesana, J., Gellynck, X., Dora, M. K., Pearce, D., \& De Steur, H. (2019). Measuring food and nutritional losses through value stream mapping along the dairy value chain in Uganda. Resources, Conservation and Recycling, 150, 104416.

Zanini, M. A. (2013). Redução do desperdício de alimentos: Estudo em um restaurante universitário. Dissertação. 159p. Mestrado em Gestão de Organizações Públicas. Programa de Pós-Graduação em Administração. Universidade Federal de Santa Maria. Santa Maria/RS, Brazil.

\section{How to cite this article}

Ouro Salim, O., Guarnieri, P., \& Leitão, F. (2021). Food Waste From the View of Circular Economy: : A Systematic Review of International Literature. Revista de Gestão Social e Ambiental, 15, e02579. https://doi.org/10.24857/rgsa.v15i1.2579 